This is an Accepted Manuscript of an article published by Taylor \& Francis in Sports Coaching Review on 07/01/2016, available online: http://www.tandfonline.com/toc/rspc20/4/1

\title{
There's more to coaching than the context: A Bourdieusian account of an embodied athlete
}

Edmund Barker, University of East Anglia; Jake Bailey, Cardiff Metropolitan University

\begin{abstract}
A growing body of work focuses on coach and athlete agency within the complex, social field of coaching. Little attention, however, has been given to athletes' life histories and how these might influence their engagement with the coaching process. The purpose of this paper is to examine how key and cumulative events in Faye's (all names are pseudonym) life influenced her engagement in distance running and with the coach with whom she worked. The findings highlight that, whilst Faye's preferences were not entirely stable, she was predisposed towards a specific type of coach, in this instance, Dave. Dave promoted working conditions that encouraged athletes to see their bodies-as-machines, to follow his orders, and not to take shortcuts. Although, on the surface, Faye 'bought into' Dave's coaching, the dialectical interactions between the established set of working conditions and Faye's embodiment raise a number of questions pertinent to coaching scholars and practitioners.
\end{abstract}

Key words: habitus, distance running, life history, athlete embodiment. 


\section{Introduction}

Recent literature has conceptualised coaching as highly contextual, social and complex (e.g. Jones, Potrac, Cushion, \& Ronglan., 2011; Denison \& Avner, 2011; Jones et al., 2004). In spite of such developments, Denison and colleagues (Denison, 2007, 2010; Denison \& Mills, 2014), largely based on empirical work in collegiate distance running, have repeatedly argued that dominant mechanistic models of coaching are still pervasive. Here, we tend to agree with Denison and Mills (2014), and hold that (distance running) coaches and scholars should become reflexive of "long-held and entrenched rational and instrumental understandings of the sporting body as a machine" (p.2). With bio-mechanistic discourses and metaphors prevailing, athletes' bodies continue to be treated as something to be dissected, manipulated, measured, and performance enhanced. This mind-set implicitly leads coaches to see corporeal movements as ontologically distinct from other psychological, social and emotional processes. To an extent, this cultivates an environment where coaches are rarely sensitised to the idea that athletes are embodied, with pasts and futures, habits and beliefs, emotions and identities, hopes and fears. The argument made here is not that (athletics) coaches are inherently devoid of, nor cannot develop, their capacities to recognise aspects of their athletes' embodiment. Neither is it to say that coaches are unable to take these aspects into account when negotiating the social landscapes in which they operate. Rather, that too often the embodied person is pushed to the margins of the coaching process and sporting practice.

The call to "bring 'people' into the study of coaching" has been heard, loud and clear (Toner, Nelson, Potrac, Gilbourne \& Marshall, 2012: 67). Research has increasingly adopted a range of sociological concepts to explain coaching practice. For example, Goffman's dramaturgical metaphor has been used to explain coaching as a social theatre, where actors perform in line with the contextual conditions of that space (e.g., Partington \& Cushion, 2012; Jones, Morgan \& Harris, 2012; Consterdine, Newton \& Piggin, 2013). Other work informed by Goffman presents coaching as a micropolitically charged and negotiated social space, within which coaches continually struggle to establish and maintain desirable 'working conditions' (Potrac \& Jones, 2009). Such conditions relate to the established rules of social and practical 
engagement in that context. Importantly, it has been noted that working conditions are not rigidly fixed; they can be "enforced, challenged and broken" by both coach and athlete (Potrac \& Jones, 2009: 560). A crucial aspect of coaching then, is to read and manage both the social landscapes that bind the activity and the individuals of whom it is comprised (Jones, Potrac, Cushion, \& Ronglan., 2011; Jones et al., 2004; Potrac et al., 2002).

As might be expected, the studies identified above have largely focused their microanalyses within the spatiotemporal boundaries of the coaching context. Whilst such studies are both interesting and illuminating, they are limited in the sense that they do not "go beyond the actions and reactions apprehended in their direct visible immediacy" (Bourdieu, 1991: 64). As such, little is known about why working conditions are accepted by some athletes and challenged by others. Research has similarly yet to explore why and how certain types of coaching conditions might impact on athletes' lives, or how athletes' formative experiences can influence the coaching process. If we start from the premise that athletes are not machines, but embodied with pasts and futures that impact on their present, we might usefully stretch our gaze beyond episodic phenomena. Exploring the embodied dimensions of coaching might offer a means through which we can begin to examine some of these questions, whilst integrating a more holistic conceptualisation of athletes (people) within coaching research.

The primary purpose of this paper was to explore the interrelationships between an embodied athlete and the working conditions of her coaching context. This was achieved through articulating experiences, perceptions, and life history of one young female middle-distance runner, Faye (all names used are pseudonyms). In making sense of Faye's biographical experiences, a Bourdieusian lens was employed to understand the importance of the embodied dimensions of coaching. Specific focus was given to examining the dialectical relationship between Faye's life outside of sport and her participation within her coaching environment.

Transcending inside-outside divisions in coaching: Habitus and the embodied athlete 
Bourdieu's (1977) description of people as 'socially informed bodies' provides a useful analogy to help us to look beyond the contexts in which coaching typically unfolds. From this perspective, athletes are conceptualised as embodied with,

\begin{abstract}
"tastes and distastes, [...] compulsions and repulsions, with, in a word, all senses, that is to say not only the traditional five senses... but also the sense of necessity and the sense of duty, the sense of direction and the sense of reality, the sense of balance and the sense of beauty... and so on." (ibid: 124)
\end{abstract}

Bourdieu's "non-Cartesian social ontology, that refuses to split object and subject, intention and cause" (Bourdieu \& Wacquant, 1992: 5), mind and body (Csordas, 1988), provides a frame which better imitates the complexity and richness of athletes' experiences. As such, a number of studies have adopted his work and thinking in their attempt to understand the coaching process. For example, using Bourdieu's model of cultural reproduction, Cushion and Jones (2014) explained socialisation processes in the field of professional football. Socialisation in this context resulted in players internalising a number of dispositions. These included "respect for authority, hierarchical awareness, control, obedience, collectivity, work ethic and winning" (p. 276). Similarly, Bourdieu's concept of capital guided Purdy, Jones and Cassidy's (2009) account of how athletes acquired, and used, forms of capital in elite rowing to negotiate power dynamics and challenge coaches. Additionally, whilst discussing how people 'learn' tennis, Strandbu and Steen-Johnson (2014) advocated habitus as a reflexive concept possessing explanatory power for understanding athlete skill development.

Habitus essentially consists of a set of malleable dispositions "“sistructured" by one's past and present circumstances, such as family upbringing and educational experiences... [and] "structuring" in that one's habitus helps to shape one's present and future practices" (Maton, 2014: 51). In this sense, a habitus is life history embodied; "it does not memorize the past, it enacts the past, bringing it back to life" (Bourdieu, 1990a: 73). Due to its embodied nature, habitus cannot be analytically constricted to the past, or to the outside of coaching. Habituses shape the enactment of the present and, therefore, the way in which coaches and athletes participate inside every training 
session. Consequently, an athlete's habitus will be influential, to some degree, in shaping his or her current practices and perceptions whilst being coached.

Athletes' habituses are constructed through the fuzzy-logic of embodying external field characteristics through social practices and positions over time (Bourdieu, 1990a; Cushion \& Jones, 2014). In addition to the internalisation of field 'structure', these embodiment processes are also attuned to the specific subjective experiences of the athlete. Not dissimilar to biographical narratives, these embodied experiences unfold chronologically over the course of an athlete's life; in doing so, unique biographical experiences construct a given habitus, through a layering process (see Brown, 2005; Reay, 2004). In turn, an athlete's habitus is comprised of physical and cognitive schemas, and can be conceived as,

"a system of lasting and transposable dispositions which, integrating past experiences, functions at every moment as a matrix of perception, appreciations and actions" (Bourdieu, 1977: 95).

Although habitus, with its complex systems and multiple layers of dispositions, accommodates high intensities of consciousness (Strandbu \& Steen-Johnson, 2014), it largely operates at the subconscious and unconscious levels (Bourdieu, 1977). This means that habituses tend to orchestrate response and perception without discursive thought. This entails that habitual tastes, dispositions, and perceptions are omnipresent, and carried with us wherever we go.

Within the perspective outlined above, athletes are embodied with schemas that (sub)consciously organise their practices and frame their social and sporting engagement. Importantly, these schemas remain intact whether the athlete is inside or outside of the coaching context. Hence, the ontological assumptions of embodiment acknowledge and emphasise that athletes do not leave their lives in the changing rooms. Instead, an embodied perspective appreciates that there is a constant dialectic between an athlete's life history and his or her current sporting engagement. With this in mind, in attempting to explore how an athlete's biographical experiences influenced her participation in, and perception of, a training environment, habitus became useful to probe and make sense of Faye's story. 


\section{Methodology}

\section{Research Design}

Faye was purposively sampled. This sampling method relies on researchers making a decision about the participant(s) that would be most likely to contribute appropriate data, both in terms of relevance and depth. To ensure that the research aims were met a sampling criteria helped inform our decision. The research participant had to be a long distance runner and part of a running club that trained regularly. The athlete must also have been willing to openly discuss their life history and the potential influences this might have had on participation in, and perceptions of, their coaching environment. Faye met such criteria; she had a story to tell and wanted to tell it.

Three, two hour, semi-structured interviews were conducted with Faye (i) to explore her life history, (ii) to obtain a description of the working conditions of her coaching context, and (iii) to explore the links between her past and her perceptions of, and participation in, her coaching environments. Drawing on Reissman's (1993) methods, the first interview was life history focused. The questioning techniques employed attempted to allow vivid experiential accounts to be told in narrative form. The principal investigator incorporated sentiments of the following phrases to guide the interview,

“Tell me in your own words... I have no set questions to ask you... I just want you to tell me about your lives... a story with a beginning, a middle [and end]... there is no right or wrong way to tell your story" (ibid: 54-5).

Faye was thus encouraged to dictate the topic of discussion, or story plot, as "how individuals recount their histories (what they emphasize or omit) has a direct bearing on what they can claim for their lives" (Sparkes, 1999: 19). Faye was asked to construct a timeline of her life with minimal guidance. She mapped key incidents onto this timeline, which acted as points for further discussion. This marked an attempt to ensure the narrative constructed was grounded in Faye's experiences, and not ascribed to her through means of unintentional coercion. In the second interview, Faye was encouraged, with similar methods of questioning, to describe the "working 
conditions' as related to coaching in which she was involved at the time (Potrac \& Jones, 2009). This included discussions around the structure, ethos, and unwritten rules of her referred to contexts. Once she had described the types of social spaces in which she trained, Faye was asked about her preferences and how she participated in the identified conditions. The final interview started with Faye elaborating on her participation in, and perception of, the coaching environments of which she was part. Following this, an attempt was made to establish links between her biographical experiences and her current experiential and participatory modalities.

\section{Analysis and representation}

The initial stages of narrative analysis involved examination of the interview transcripts for key incidents and important themes (Reissman, 1993). Anger, dependancy, resistance, alienation, fear, and ambition were identified as powerful themes in Faye's life history and sporting experiences. These themes were created in a process similar to the open and axial coding characteristic of grounded theory methodologies. However, unlike other qualitative coding methods, "the outcome of narrative analysis is a narrative" (Oliver, 1998: 250). A process of narrative construction, therefore, followed the initial coding. In constructing these narratives, it was important to be sensitive that events in Faye's life happened at specific times. Careful attention was given to portray Faye's experiences within this temporal order, as narrative analysis is bound by such a structure (ibid). When constructing the narratives, only raw data that pertained to a particular moment were featured within the text. Nevertheless, the narratives presented in the discussion were subject to a process of interpretation and construction by the first author. Consequently, the product cannot be considered a purely organic reflection of Faye's experience.

Faye's embodied experiences had to be remembered and verbalised, losing purity in recall and translation. For instance, in selecting the words to describe her experiences, Faye invested in portraying the past and present in a particular light and within a narrative structure (Sparkes \& Smith, 2011). Once spoken, Faye's experiences were further reduced through transcription. As stated, in the process of analysing and (re)writing Faye's stories, the complexities of experience were 
unavoidably interpreted and refined by the authors. Finally, Faye's experiences are recontextualised by those who read this text, as such readers bring their own subjectivity and history to bear on the story (Stone, 2009). This openness to (re)interpretation(s), however, provides Faye's narratives with the potential to provoke reflection upon personal understandings and practice.

In order to mediate some of the problems of representation listed above, on numerous occasions from data collection to publication (including the final draft) Faye was invited to check, clarify, and expand on the text presented and the discussion offered. This process comprised several informal conversations, which were valuable in terms of checking the authors' interpretations, and to provide confidence about the trustworthiness of the constructed narratives (Reissman, 1993).

Within the discussion, data are not only presented in narrative form but also as direct transcription. To mark the difference between types of data, constructed narratives are block indented whereas direct extracts feature within the main body of text encased in quotations. In presenting both forms of data, inconstancies with tense emerged. Direct quotations adopt the tense spoken within the interview while narrative sections often utilised a range of tenses. Voicing Faye's experiences in this manner marked an effort to provide the reader with a rich and engaging narrative, whilst reflecting storytellers' tendencies to fluctuate between the past, present, and hopes future in explaining how these are interconnected (Sparkes \& Smith, 2011).

After the narratives were initially drafted, habitus acted as a lens to probe the deeply buried interactions between the inside and outside of coaching. Incorporating theory into this narrative approach can, according to Sparkes (1999), induce new understandings of the stories and their interrelations. With this intention, and working from the central narrative themes, the data were deductively handled into aspects of a habitus. In reality then, the inductive-deductive analysis carried out (a process of narrative construction coupled with a Bourdieusian analysis) were rarely distinct stages.

\section{Faye's story}


At the time of the interviews, Faye was a nineteen year old middle-distance runner who trained up to ten times a week. Faye outlined 'working conditions' representative of the coaches and spaces where she trained (Potrac \& Jones, 2009). The way in which she engaged in, and perceived, her coaching contexts appeared to be influenced by her life experiences and subsequent habitus formation. Whilst this might be an obvious conclusion, the data also highlighted how particular forms of athlete embodiment mixed with specific sets of established working conditions created moments of contestation, docility, and distress. In order to raise these issues, the discussion that follows charts Faye's perceptions of, and participation in, her home running club, where Dave was her coach. The opening section introduces Dave and the working conditions of his sessions. Through Faye's account, a sense of how she tended to conduct herself in this environment is outlined, whilst identifying how engagement in Dave's training group influenced her outside life. Next, we provide a refined version of Faye's important formative experiences that shaped her embodied self; this is given in an attempt to explain Faye's positive perceptions and compliance with the working conditions established by Dave. In the final section, we foreground some moments of conflict and ambiguity which are better understood when considering Faye's habitus as 'multi-layered' and constitutive of both her early and later experiences (see Reay, 2004, Brown, 2005). At this juncture, a more critical stance on the dialectical relationship between Faye's habitus and the working conditions of Dave's sessions is adopted.

\section{Faye, Dave and distance running}

When Faye first encountered Dave, at the age of fifteen, her life was in crisis. This made distance running of particular importance as she joined the club when she was in transition and explicitly looking to change herself. Faye 'bought into' Dave's coaching because running gave her corporeal pleasure, structure, and a way to succeed and prove people wrong.

Coming to depend on running and structure: "It has changed me" 
Looking back I can explain why I love running. It gave me focus; it made my body feel good. I loved the training, you had to do it every day to get better. Running gave me structure and something positive to do. It didn't take me long before I felt confident at my running club, like I could achieve. I realised that I had to keep on working hard to get somewhere, to catch up with other people. But I believed that it could help me change things in my life.

My coach, Dave, has always given me targets; always pushed me to go faster. It's been hard work and a long road, but I have, and will improve. I know that because of everything that it has done to me, I completely love running! I want to do well. It has changed me!

Faye's claims were indicative of her belief that her engagement with Dave changed her life, and that this was something she embraced and desired. This offers a first insight into the dialectical relation between the inside and outside of Faye's sporting experience. In order to further explore this key focus of the paper, it is necessary to provide a sense of the working conditions Faye experienced in her training sessions with Dave. Of course, Faye's accounts are likely to have been influenced by her adulation of Dave and his role in changing her life path. However, through the interview process she showed herself to be well positioned to describe Dave's coaching environment(s) and ethos.

According to Faye, Dave's sessions were ultra-structured and repetitive. The warm up was the same each week and Faye knew exactly what she was meant to do at any given moment. Additionally, Dave would ensure he was available for a telephone meeting every day, at a set time, to discuss training. Within the training sessions, conversations were restricted; any talking afterwards was always about running and diets. Dave was very authoritative, dictating outcome goals for the athletes. He told athletes exactly what they should aim to achieve, and how this should be operationalised. Drawing on training principles rooted in discipline such as biomechanics, nutrition and physiology, Dave planned each training programme. $\mathrm{He}$ also tailored athletes' workloads specifically to maximise progression. Consequently, within this group, there were strong hierarchal coach-athlete power relationships that were rarely challenged. Dave had cultivated a 'serious' atmosphere, where complete dedication was necessary. In being a member of this club, therefore, particular and 
compliant bodily practices were both expected and required. These encroached onto the athletes' lifestyles, from social curfews to dietary regimes.

Faye grew to (generally) respond well to this type of coaching; she became socialised to accept it as normal became her preferred style. Embodying a particular set of qualities was crucial for engaging in Dave's context; athletes unable to adapt, and adhere, to these structured conditions tended to quit. As Faye recognised, Dave "has made people not run again because the amount he has told them to do". Before key events in her life, and transformations to her habitus that occurred over a process that lasted years, Faye might have shared the same fate as these athletes. She would have likely lacked the embodied dispositions to run for Dave. This was not, however, the case, and it is an important intention of this paper to explore why.

\section{Faye's life history: early dispositions}

Before Faye's life transition started, and before she began running, her dispositional call to action when being told what to do normally resulted in angry outbursts. The habitual nature of this response was most apparent in her school setting.

\section{'Being told what to do': The anger response}

Just been kicked out of R.E again. I'm in the corridors when my head of year finds me and tells me that I need to change. I need to change? WHY is he telling me what to do?!?! It's got nothing to do with him. I let him know that he is out of order. Then it kicked off, he got in my face, started shouting, pointing, and stuff. When things like that happen it gets me angry. I'm like, back off!!!

Faye's habitual response was to feel anger when a person in authority sought to control her. Rebelling against teachers, parents and, on occasions, police, was part of her identity performance; an identity in line with her 'crowd'. An anger response was developed as central to the emotional output of her habitus; this often resorted to acts of aggression at school, home and recreational environments. At this time in her life, there was some logic behind Faye's embodied responses when considered in terms of the social dynamics in which she was situated (Bourdieu, 1990a). It could be 
argued that Faye's embodied responses protected her social capital, whilst simultaneously contributing to the reproduction of defining field struggles between the 'crowd' and authority (teachers, police and parents). Her embodied 'anger response', however, did not survive what was to happen in her life, as the logic serving the practice was interrupted by what Joas (1996) described as a crisis. Crisis in this sense is described as what had "previously been a habitual, apparently automatic procedure of action, is interrupted" as it no longer yields the same rewards (Joas, 1996: 128).

Age 14: "Everything went a bit downhill"

\begin{abstract}
Finally, the school have said they have had enough of me. I understand why, but I never thought it would happen: EXPELLED! How can they reject me just like that? All they have ever done is tell me what to do and put me down. Now I have got the disappointment of my family to deal with. I do sort of feel bad for them, you know, they are so upset. But I don't care; I wouldn't mind being expelled as long as I could spend the days with my mates again. It's so boring sitting at home, arguing with mum. Am I wanted anywhere? I don't think I can do anything right. None of the schools round here will take me. Mum is trying really hard to get me back in - But Only Two! ... Two out of six are even considering it. I'll tell you what is $\mathrm{p}^{* *}$ sing me off, I know what school I want to go to out of the two, but I'm not being given the choice. Mum won't let me go to it because apparently I know too many people there; she thinks that if I don't hang out with them I will behave. All it will achieve, by taking me away from them, is to frustrate me. At least my Mum is trying to help Dad has lost interest, he's silent most of the time.
\end{abstract}

There was both pressure and action beyond Faye's control (by school and family) to remove her from her proximal field position and practices. This dislocation plunged Faye into crisis, by rupturing the logic of Faye's anger response (among other aspects of her habitus and identity). The intervention disjointed the quasi-unity between habitus, practice, capital and field position. Within these new settings, removed from the 'crowd', Faye could no longer amass capital by continuing to ignore or challenge authority. This was not least because there was little value associated with these responses within her new peer group. 


\section{Initiating the re-laying of Faye's habitus}

"Habitus is a kind of transforming machine..., but in a relatively unpredictable way, in such a way that one cannot move simply and mechanically from knowledge of the conditions of production to knowledge of the products" (Bourdieu, 1990b: 87).

Faye did not change immediately. She only felt alienated; the new (school) environment did not make sense. She thought it was "weird because everyone was doing work in lessons... and everyone was quiet". She noticed that people would look at her strangely when she behaved in her usual manner. As the hysteresis effect (Bourdieu, 1977) was acting on Faye, a combination of external factors prompted her to re-evaluate how she wanted to act.

Some things still got me really angry; only three days in and I got in a fight. Normally I would have been suspended for this, but not here, they knew that I could improve.

My new head of year made it easier. I preferred her to my old one; he used to say, "I was either going to end up dead or in prison". I remember people used to think I couldn't do anything... I began to want to prove them wrong!

Faye's decision to 'prove them wrong' initiated an erosion of her once durable habitus. In this re-layering process (Brown, 2005; Reay, 2004), her anger response was superseded by a desire to be told what to do as she came to see this linked to her ability to succeed and, thus, prove others wrong. Exploring this change in disposition became an important focus of this paper due to its centrality in Faye's life and as a necessary condition of her engagement in her coaching environment.

The initial catalyst for the change in Faye's disposition was the move to another school and exposure to a contrasting social and educational environment. Here, she no longer had regular opportunities to be part of the 'crowd', whilst her new teachers provided support to help Faye adjust to amended structures. Additionally, and importantly, Faye was introduced to running, to new social groups and to Dave. 
Joanne, a new friend from school was a runner. She asked me if I wanted to go for a run with her. I had nothing better to do because I didn't see my old friends as often. The first club session I ever went to was so amazing; I couldn't really explain the feeling. It was hard work, I didn't realise all the preparation that went into distance running. The head coach, Dave, he was so organised and passionate, the club success was massive. After that session I thought the next step was to join up and give it a go. I thought it would show a few people!

Faye chose to become a runner, in part because she enjoyed the embodied experiences of running, but also, as an attempt to gain capital in her new setting. Her embodied transformation, started in school, was further facilitated in a sporting context. This involved a reflexive process that questioned her position in relation to others, her trajectory and (re)forming goals. Importantly, running had become a legitimate option within her social group (Bourdieu, 1977). This was meaningful, as distance running became an activity through which Faye could accrue physical, social, and symbolic capital. Running was to become an important vehicle in improving her status or field positions, achieving success and thus proving people wrong. It was, perhaps, for these reasons that her running club and head coach Dave were allocated considerable symbolic status in Faye's biographical narrative.

As stated, running had a crucial role in the dispositional transformations that occurred. Simultaneously, other influences outside of coaching also had an impact on these embodied transitions. After she finished school, her time at college (studying A levels) cannot be overlooked. In college, Faye received a rigid timetable of activities and was told exactly what she needed to do,

"I liked College because of the structure of it, and it was proven that it was successful. All the hard work gave me the good grades"

Through a combination of both educational and training experiences Faye came to associate participating in highly structured environments with success. Structured environments came to be perceived in a positive light as Faye continued to work towards correcting her deeply embodied 'anger response'. From starting to run and 
over the course of these college years this aspect of Faye's habitus was significantly reconfigured.

Faye's habitual responses drastically changed in regards to being told what to do. From this period onwards Faye expressed "I just need someone to tell me what to do". This new disposition transcended educational and coaching contexts, it shaped her practices both inside and outside of school and running. When explaining why she pushed through pain barriers, restricted her eating habits, regulated her social life, and trained with such frequency Faye said "you just do it because you've just been told to do it".

\section{Coming to embody an athletic identity}

Allen-Collinson (2011) argued that female runners bodies' are an essential part of their identity. In addition to this, Shilling (2012) recognised body projects have become central to constructing identities in late modernity. In line with both AllenCollinson and Shilling, Faye placed her body at the centre of her identity; treating it as a biological resource that could be enhanced to achieve the changes she was attempting. Faye, at first, incorporated body disciplines through observing others; "you can see the success... people that do not drink, and eat well, are doing really well for themselves". However, just as importantly, her scientific, biomechanical, nutritional and physiological knowledge (learned at college) acted as internal surveillance. As running became her most valued identity, she described the activity as a discipline that began to stretch beyond training into her lifestyle.

"I need to run every day... I get tired and sometimes I don't want to go out for a run, but at the same time I do it... People try to encourage me to eat fatty foods and stuff, you have to be strict with yourself... I know that I have to buy apples and crackers to make sure I keep my weight low... The reason is because my performance... I think you need to be pushed through the pain barrier, otherwise you're not going to achieve anything"

Her running project, presupposes the metaphor of her "body as [a] machine" (Shilling, 2012: 40); her explicit goal was to become a 'machine', a running machine. This is not an uncommon discourse, or desire in sport (Shilling, 2012), not least in distance running (Denison \& Mills, 2014). Faye embodied this metaphor, at 
times suppressing emotions and physical pain to adhere to it. This body project and the associated regimented, mechanistic, mentality of sporting performance aligned with Dave's working conditions, and further supported Faye's acceptance of it and the further re-layering of her habitus.

\section{Further thoughts on Dave}

Through the discussion, we have outlined that Faye constructed a new identity, one centred on running. An outcome of this transition was that Faye came to embody many of the required dispositions and habits to sustain participation and 'buy into' Dave's structured conditions. Early reviewer comments raised questions about the extent to which an athlete might move from being rebellious to authority to compliant, and the process which underpinned it. As explained above, this change largely occurred as a result of coming to believe that being told what to do would lead to the success she required to prove people wrong. Here, however, we agree with the reviewer in that the magnitude of the change is such that it requires further exploration. In particular, it seems necessary to explicate Dave's important role in facilitating this process. What was it about him that led her to place so much trust in another person and to allow his direction to scaffold her changing identity and practices? This question is similar to that posed by Jones, Bailey, Santos and Edwards (2012), where focus was placed on who the coach was (to athletes) and how this mediated every aspect of the coaching process. It is a question brought into even starker contrast here, where the capacity of the coach to influence all aspects of an athlete's identity and life, both inside and outside of coaching, has been identified.

In an earlier section, the working conditions of Dave's sessions were somewhat outlined. These working conditions were an important part of the dialectical process which led to Faye's transition and to her acceptance of Dave's coaching. Faye came to believe that being told what to do (by Dave in particular) would lead to success,

"[Dave] will tell you in a race where he wants you to come... Dave will constantly be like no drinking, no fatty foods, no late nights... [He says] 
you have got to eat well... I think that if you want to get to the top, he is the man to go to."

Whilst this is, of course, important, it may not be the whole story; would Faye have changed her disposition and outlook for another coach in the same way that she did for Dave? After all, here we are talking about a transition that ranges from outright rebellion to a largely compliant athlete with a preference for external direction. In this regard, Faye's view of Dave as exceptional and 'seriously dedicated' was perhaps an important mediating factor in her change. Faye was impressed that Dave trained on Christmas Day, a signification which typified Dave's coaching approach. He was exceptionally organised, a meticulous planner, and a provider of time intensive support to Faye's running.

Faye talked about her aspirations to achieve this level of commitment, although at the time of the interviews Faye recognised that she was "not there yet". By following everything Dave told her, Faye believed that she was moving towards this end, whilst cementing her identity as a 'running machine'.

\section{Moments of contestation and distress}

Dave's importance in Faye's story, her perception of his commitment to her training and centrality in achieving success, may have been mediating factors in her generally positive view of him, and her acquiescence to his authority. In turn, because many of her team mates shared common interests and dispositions, Dave's tough and mechanistic approach was largely accepted. Here we note that compatibility between working conditions and shared dispositions may help develop 'smooth' training environments, which have the capacity to be productive in terms of performance enhancement. In such situations, however, there will inevitably be unintended consequences (see Giddens, 1984). Not all of these will be positive, and at times can be counterproductive. In Faye's case, this is best illustrated through examples of injury. Here, her dependency on being told what to do, and habitual compliance to Dave's orders, resulted in numerous injuries.

"I told Dave about a knee injury. I had told him I was in pain, as he always has a go if you don't tell him before the session. But I always feel 
like I have to push through an injury for fear that he won't respect you as an athlete. I never have an issue with pushing, but then part of me feels he should be the one telling me to stop. At no point did he say stop, so I carried on..."

This incident highlights that the established working conditions for athletes who invest in becoming machine like and embody a disposition related to being told what to do, create the potential for injury. This might be seen as a problematic unintended consequence, as injury can threaten athletes' wellbeing as well as interrupt the coaching process. Faye's willingness to follow Dave's instructions against the subjective knowledge of her own body, was emblematic of a wider issue. Faye stated that "quite a lot of girls come out with stress fractures and things like that because he pushes people to the limits". Whilst Dave's athletes seemingly wanted to train to their physical limits, they were predisposed to ignore their bodies' thresholds to complete what they were told to do. Faye was no exception. Although maximising athletic effort can be an essential ingredient for elite performance, environments that value athletes who push through injuries can clearly be dangerous. Dave's conditions encouraged Faye (who sought social capital within the group) to ignore bodily damage in pursuit of the 'respect' pushing through related discomfort might produce. The argument made here is that the increased likelihood of injury occurring was not only set by the coaching conditions but the way in which Faye (and other athletes) engaged with them.

Injuries were not the only issue identified as a result of the interaction between the established coaching conditions and Faye's embodiment. Faye's deeply buried 'anger response' occasionally rose to contest Dave's authority. Faye recognised this, stating that "sometimes little bits come out of what I used to be like. Just tiny bits, especially if something gets on my nerves... I still sometimes get a bit aggressive". For example, on one occasion, Faye became angered and threw her phone across the room after a telephone conversation with Dave about her training programme. Such critical incidents are reflective of Bourdieu and Wacquant's (1992) claim that sediments of early dispositions are lodged inside the body and await reactivation. As such, Faye demonstrated a variety of embodied responses to similar situations which 
revealed the multi-levelled, multi-dimensional nature of the habitus (Reay, 2004; Brown, 2005).

\section{Concluding thoughts}

In sharing Faye's story, we hope to sensitise practitioners to the idea that athletes are embodied; with pasts and futures, habits and beliefs, emotions and identities, hopes and fears - all of which are carried into the coaching context. However, this in itself provides no answers or practical guidelines. It is not pragmatic, or desirable, for coaches to examine empirically each athlete's 'embodiment' and modify practices accordingly. Even if Dave had the requisite insight into Faye's outside life, it would not prevent, or resolve, potential moments of contestation. Nor would it recondition the working environment, or Faye's embodied dispositions, making injury less likely. Despite providing rich details regarding a number of dialectical transferences that impact upon the coaching process, the way in which Dave should, and could, tailor his current practices remain unclear. Not least, because pedagogical approaches that intend to individually cater for everyone are unrealistic, and have been criticised elsewhere (e.g., Jones \& Standage, 2006; Jones \& Wallace, 2005).

Faye's story, however, vividly illustrates the power coaches can have in shaping the identities and experiences of those they coach. The influence Dave had on Faye, and other athletes, was shown to come with wider responsibilities that are, perhaps, overlooked. Even when athletes 'bought into' Dave's working conditions it was clear that the outcomes were not neutral. Most noticeably, Faye's description of injury, strict eating habits, and social curfews raise ethical considerations regarding the impact of such coaching practices on Faye's life. For others, these conditions proved too much who then removed themselves from the tough regime. For Faye, however, conforming to Dave's working conditions became central to her changing identity. She came to embrace practices associated with the body-as-a-machine metaphor (Shilling, 2012; Denison \& Mills, 2014), and desired to be coached as such. Many of Faye's experiences, inside and outside of coaching were, therefore somewhat contradictory to the idea that coaches should "challenge the dominance that certain sport sciences, such as exercise physiology and biomechanics, have in shaping the 
understanding of the body in performance" (Denison \& Mills, 2014: 14). Faye's choice to become a distance runner was, in part, influenced by Dave's unquestioned commitment to reproducing a set of coaching conditions rooted in these disciplines.

Whilst it might not always be beneficial, practical, or possible to fully attend to the embodied athlete, research that focuses on understanding athletes as embodied might still make a contribution to the oft cited, yet still developing, complexity of coaching argument. Faye's experiences indicated that the kind of complexities involved in coaching distance runners (Denison \& Mills, 2014) may often be connected to athletes' embodied history. Faye's changing embodiment meant that there were times when she would have had no interest in being coached, or been uncoachable, due to her reaction to authority. Specific, and largely unpredictable, circumstances shaped moments that created in Faye a love of athletics and her immersion in a coach-athlete relationship that became central to her developing identity. Such events cannot be predicted, and are difficult to explain after the fact; perhaps, contributing to and strengthening claims regarding the ambiguous and unpredictable nature of coaching.

\section{References}

Allen-Collinson, J. (2011). Feminist phenomenology and the woman in the running body. Sport, Ethics and Philosophy, 5(3), 297-313.

Bourdieu, P. (1977). Outline of a theory of practice. Cambridge: Cambridge University Press.

Bourdieu, P. (1990a). The logic of practice. Cambridge: Blackwell Publishers Ltd.

Bourdieu, P. (1990b). Sociology in question. Cambridge: Polity Press.

Bourdieu, P. (1991). Language \& symbolic power. (J. B. Thompson, Ed.). Cambridge: Blackwell Publishing Ltd.

Bourdieu, P. \& Wacquant, L. (1992). An invitation to reflexive sociology. Cambridge: Polity Press.

Brown, D. (2005). An economy of gendered practices? Learning to teach physical education from the perspective of Pierre Bourdieu's embodied sociology. Sport, Education and Society, 10(1), 3-23. 
Consterdine, A., Newton, J., \& Piggin, S. (2013). 'Time to take the stage': a contextual study of a high performance coach, Sports Coaching Review, 2(2), 124-135.

Csordas, T. J. (1988). Embodiment as a paradigm for anthropology. Ethos, 18, 5-47.

Cushion, C., \& Jones, R. (2014) A Bourdieusian analysis of cultural reproduction: socialisation and the 'hidden curriculum' in professional football. Sport, Education and Society, 19(3), 276-298.

Denison, J. \& Avner, Z. (2011). Positive coaching: Ethical practices for athlete development. Quest, 63, 209-227.

Denison, J. (2007). Social theory for coaches: A Foucauldian reading of one athlete's poor performance. International Journal of Sports Science \& Coaching, 2(4), $368-383$.

Denison, J. (2010). "Messy texts", or the unexplainable performance: Reading bodies' evidence. International Review of Qualitative Research, 3(1), 149-160.

Denison, J., \& Mills, J. (2014) Planning for distance running: coaching with Foucault. Sports Coaching Review, 3(1), 1-16.

Giddens, A. (1984). The constitution of society: Outline of the theory of structuration. Cambridge: Polity Press.

Joas, H. (1996). The creativity of action. Cambridge: Polity Press.

Jones, R. L., Armour, K. M., \& Potrac, P. (2004). Sports coaching cultures: From practice to theory. London: United Kingdom: Routledge.

Jones, R. L., Bailey, J., Santos, S. and Edwards, C. (2012). Who is coaching? Developing the person of the coach. In D. Day (Ed.), Sports and coaching: Pasts and futures (pp. 1-12). Crewe: MMU Institute for Performance Research.

Jones, R. L., Morgan, K., \& Harris, K. (2012). Developing coaching pedagogy: seeking a better integration of theory and practice. Sport, Education and Society, 17(3), 313-329.

Jones, R. L., Potrac, P., Cushion, C. \& Ronglan, L.T. (2011). (Eds.) The Sociology of Sports Coaching. London: Routledge.

Jones, R. L., \& Standage, M. (2006). First among equals: shared leadership in the coaching context. In: Jones, R.L, (ed). The Sports Coach as Educator: Reconceptualising sports coaching. Oxon: Routledge (pp. 65-76). 
Jones, R.L., \& Wallace, M. (2005). Another bad day at the training ground: Coping with ambiguity in the coaching context. Sport, Education and Society, 10(1), 119-34.

Maton, K. (2014). Habitus. In N. Grenfell (Ed.), Pierre Bourdieu: Key Concepts (2nd ed.) (pp. 48-65). New York: Routledge.

Oliver, K. L. (1998). A journey into narrative analysis: A methodology for discovering meanings. Journal of Teaching in Physical Education, 17, 244-259.

Partington, M., \& Cushion, C. J. (2012). Performance during performance: Using Goffman to understand the behaviours of elite youth football coaches during games. Sports Coaching Review, 1(2), 93-105.

Potrac: , \& Jones, R. L. (2009). Micropolitical workings in semi-professional football. Sociology of Sport Journal, 26(4), 557-577.

Potrac, P., Jones, R. L., \& Armour, K. M. (2002). 'It's all about getting respect': The coaching behaviors of an expert English soccer coach. Sport Education and Society, 7(2), 183-202.

Purdy, L., Jones, R. L., \& Cassidy, T. (2009) Athletes' use of capital in negotiating their experiences in an elite men's rowing programme. Sport, Education and Society, 14(3), 321-338.

Reay, D. (2004). 'It's all becoming a habitus': beyond the habitual use of habitus in educational research. British Journal of Sociology of Education, 25(4), 431-444.

Reissman, C. (1993). Narrative analysis. London: Sage

Sparkes, A. C. (1999). Exploring body narratives. Sport, Education and Society, 4(1), 17-30.

Sparkes, A. C., \& Smith, B. (2011). Inhabiting different bodies over time: narrative and pedagogical challenges, Sport, Education and Society, 16(3), 357-370.

Stone, B. (2009) 'Running man'. Qualitative Research in Sport and Exercise, 1(1), $67-71$.

Strandbu, A., \& Steen-Johnsen, K. (2014) Bourdieu knew more than how to play tennis! An empirically based discussion of habituation and reflexivity. Sport, Education and Society, 19(8), 1055-1071.

Shilling, C. (2012). The body and social theory (3rd ed.). London: Sage Publications. 
Toner, J., Nelson, L., Potrac, P., Gilbourne, D., \& Marshall, P. (2012). From 'blame’ to 'shame' in a coach-athlete relationship in golf: A tale of shared critical reflection and the re-storying of narrative experience. Sports Coaching Review, $1(1), 67-78$. 